\title{
Nonpuerperal inversion of uterus secondary to leiomyoma in menopause: a rare case report
}

\author{
Kalarani E., Amudha P.*, Rubini M., Karthika Devi A.
}

Department of Obstetrics and Gynaecology, Thanjavur Medical College, Thanjavur, Tamil Nadu, India

Received: 03 June 2016

Accepted: 01 July 2016

*Correspondence:

Dr. Amudha P.,

E-mail: amudha70dr@gmail.com

Copyright: $\odot$ the author(s), publisher and licensee Medip Academy. This is an open-access article distributed under the terms of the Creative Commons Attribution Non-Commercial License, which permits unrestricted non-commercial use, distribution, and reproduction in any medium, provided the original work is properly cited.

\section{ABSTRACT}

Inversion of uterus is a rare clinical condition if not associated with third stage of labor or puerperium. Non-puerperal uterine inversion usually occurs secondary to tumor arising from the fundus of uterus. We report an unusual case of non-puerperal uterine inversion caused by large submucous fibroid in a 65 year old postmenopausal woman which was managed by combined abdomino-perineal approach.

Keywords: Uterine inversion, Non-puerperal, Submucous fibroid

\section{INTRODUCTION}

Non-puerperal uterine inversion has been described as a rare occurrence by several authors but how really rare is it has not been defined. ${ }^{1}$ However, the fact that many gynaecologists might not see one in their entire practice, gives a clue as to its infrequent occurrence.

Other than intrauterine pathology like fibroid with fundal attachments and polyp, other factors like thinning of uterine walls from the base of the tumor and pressure atrophy, sudden emptying of uterus which was previously distended by tumor may also contribute to uterine inversion. ${ }^{2}$.

Common clinical features are chronic vaginal discharge and anemia due to heavy irregular uterine bleeding. ${ }^{3}$ Some women may present with voiding difficulties and lower abdominal heaviness.

Recto-abdominal examination is the most diagnostic clinical method as vagina is occupied by the inverted uterus and on bimanual examination, dimpling of uterine fundus can be made out depending on the stage of uterine inversion. Treatment is based on stage of inversion and associated pathology.

\section{CASE REPORT}

We report a case of multiparous, postmenopausal lady with previous history of 5 successful vaginal deliveries who presented to our hospital with complaints of abdominal pain, mass descending per vaginum and foul smelling vaginal discharge for 6 months. She had no voiding difficulties. No other medical or surgical comorbidities were present.

On examination, patient was cachexic and anaemic with normal vitals. Abdominal examination was unremarkable. Vulval examination revealed a large irregular, highly congested, tender mass of $15 \times 10 \mathrm{cms}$ lying outside introitus with multiple ulcers covered with slough and purulent discharge. The mass was irreducible and on per rectal examination the uterus could not be felt.

On pelvic ultrasound, uterus could not be identified and that increased the suspicion of uterine inversion. Anemia was corrected with 3 units of packed cell transfusion. Patient was treated with parenteral antibiotics based on culture and sensitivity. Following antibiotic treatment and reduction in edema and congestion of the prolapsed mass, it was possible to delineate the inverted uterus and its cervical rim the submucous fundal fibroid and the 
partially eventerated vagina. Considering her age and postmenopausal status, hysterectomy was planned.

Intraoperatively, the submucosal fibroid was excised vaginally to facilitate reduction and then on laparotomy, the diagnosis of uterine inversion was confirmed by the typical "flower pot appearance of the inverted uterus, round ligaments and fallopian tubes seen within the depression.

Inversion was corrected by Haultain's procedure by incising the posterior cervical rim in midline followed by total abdominal hysterectomy with bilateral salphingooopherectomy. Post-operative period was uneventful. She was discharged on $7^{\text {th }}$ post-operative day. Histopathological examination confirmed it to be leiomyoma with necrosis.

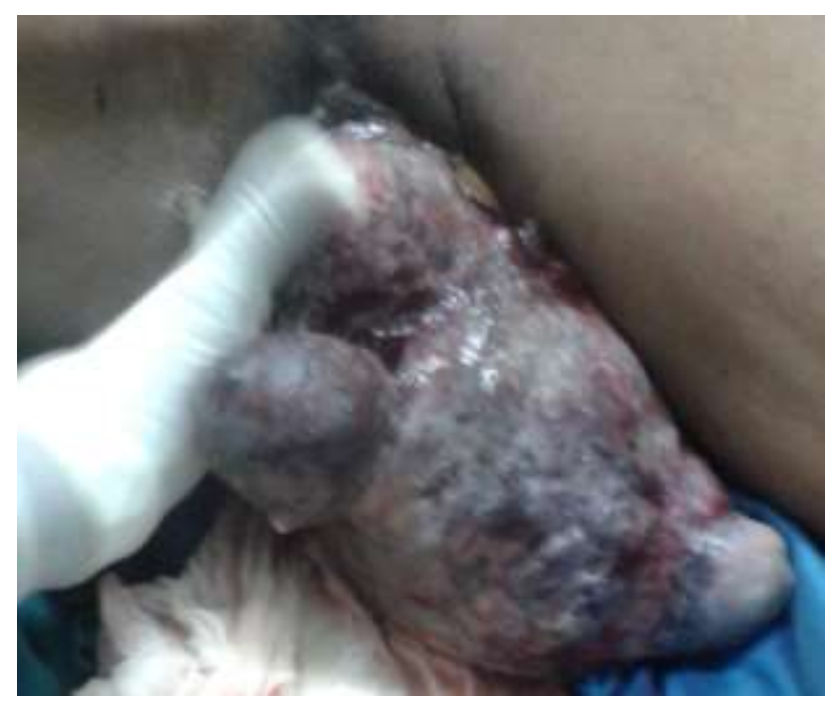

Figure 1: Inverted uterus on admission.

\section{DISCUSSION}

Non-puerperal inversion of uterus is a rare clinical condition and hence it remains a diagnostic dilemma and treatment challenge. ${ }^{4}$ There are no exact figures on the incidence of it in the literature. Mivinyoglee et al reported that $97.4 \%$ of uterine inversions are associated with tumour, out of which $20 \%$ were malignant, while Takano et al found that $71.6 \%$ of cases were associated with leiomyoma. ${ }^{5}$

Based on the degree of uterine inversion, four distinct stages have been described. ${ }^{6}$

Stage 1 - Inversion of uterus is intrauterine/incomplete. Fundus remains within the cavity.

Stage 2 - Complete inversion of the uterine fundus through the fibro muscular cervix

Stage 3 - Total inversion, where by the fundus protrudes through the vulva.
Stage 4 - Vagina is also involved with complete inversion through the vulva along with inverted uterus

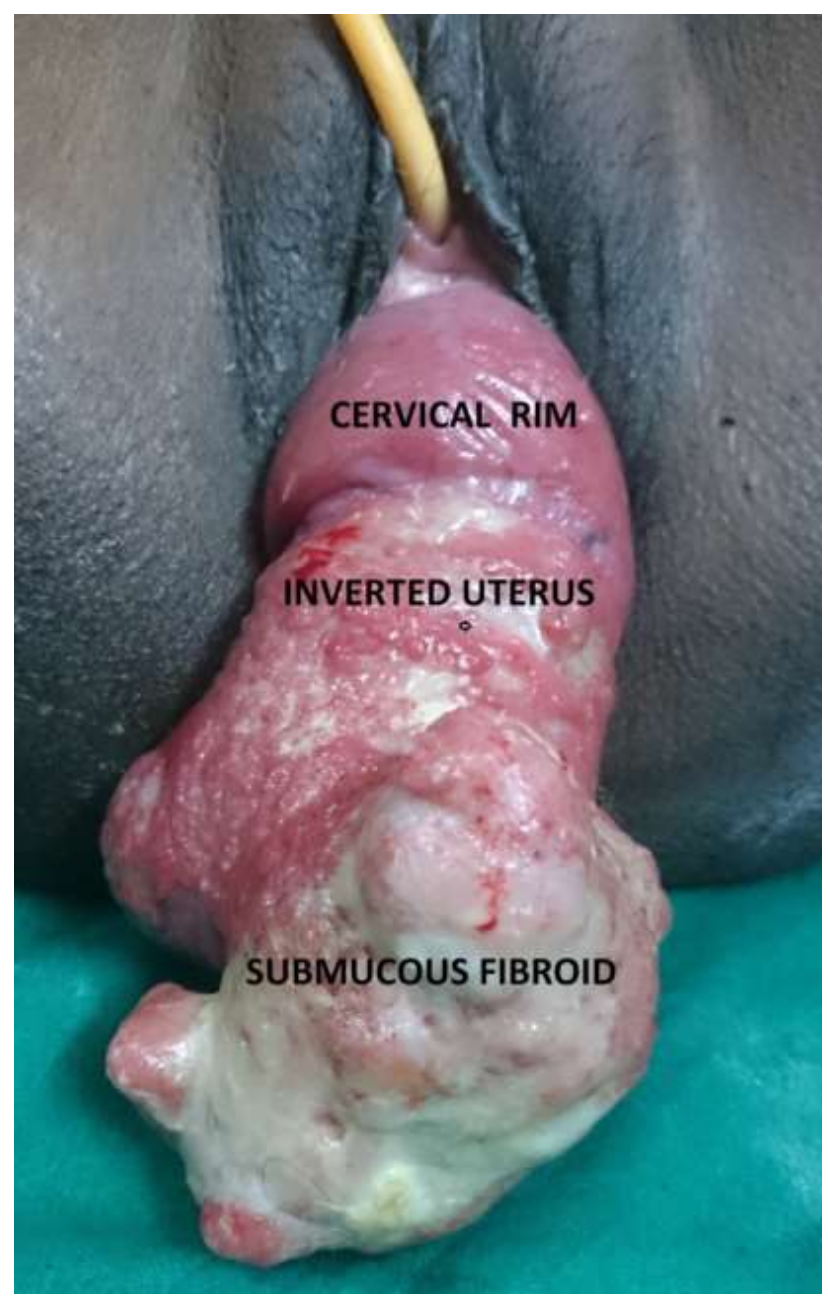

Figure 2: Inverted uterus after 2 weeks.

Due to its insidious onset and rare occurrence, the clinical diagnosis of chronic uterine inversion is difficult, more so if inversion is incomplete. Diagnosis requires a high index of suspicion when tumor is palpable in vagina or seen out of introitus and uterine fundus is not palpable on bimanual examination. Ultrasound examination is the first line imaging investigation. ${ }^{7}$ USG features include indentation of fundus and depressed longitudinal groove extending into the centre of the inverted uterus. MRI is also helpful in diagnosis. U shaped uterine cavity, a thickened and inverted uterine fundus on sagittal section and a "bulls eye" configuration on an axial image are the described MRI findings of uterine inversion., 8

Surgical treatment depends on patients' fertility, stage of inversion and associated pathology. Many abdominal and vaginal surgical approaches have been described to correct inversion. Spinelli and Kustner are trans-vaginal repositioning techniques and the Huntington's, Haultain's and Dobbin's procedures are trans-abdominal techniques. $^{10,11}$ 
Haultain's procedure uses a vertical incision in the posterior portion of ring with gentle traction on the round ligaments. If a hysterectomy is to be performed, reposition is always done first, because hysterectomy on the inverted uterus is associated with difficulty in identification of the peritoneal pouches, and also associated with a greater risk of injury to the urinary bladder and ureters ${ }^{2}$. In our case also, the same was followed.

\section{CONCLUSION}

Non-puerperal uterine inversion is an unusual condition. Clinical diagnosis is often not easy and sometimes this situation can prove to be fatal. A high index of suspicion is necessary for diagnosis when a large prolapsed fibroid is encountered, as the uterus perse may not be palpable on examination. Uterine inversion has a good outcome if diagnosed and managed timely. Repositioning of uterus alone may not be possible in all cases, leaving hysterectomy as the only option as in our case.

Funding: No funding sources Conflict of interest: None declared Ethical approval: Not required

\section{REFERENCES}

1. Ashraf-Ganjooie T. Non-Puerperal Uterine Inversion. A Case Report. Archives Of Iranian Medicine 2005;8(1):63-6.

2. Kagne SS, Thawal YA, Tambe SG. An Extremely Rare Case Of Chronic Non Puerperal Inversion
Treated By Myomectomy Preceding Vaginal Hysterectomy. Journal Of Evolution Of Medical And Dental Sciences. 2013;46:8976-9.

3. Eigbefoh JO, Okogbenin SA, Omorogbe F, Mabayoje PS. Chronic Uterine Inversion Secondary To Submucus Fibroid- A Case Report. Niger J Clin Prac. 2009;12:106-7.

4. Jain S, Aherwar R, Joshi P. Chronic Non Puerperal Uterine Inversion; Fibromyoma Uteri as a Cause- A Case Report. Sch J Med Case Rep. 2014;2(2):100-2.

5. Mivinyoglee J, Simelela N, Marivate M. NonPuerperal Uterine Inversions. A Two Case Report And Review Of Literature. Central African J Med. 1997;43:268-71.

6. Skinner GN, Couden KA. Non-Puerperal Uterine Inversion. Gynecol Obstet Mex. 2005;73:328-31.

7. $\mathrm{Hu} \mathrm{CF}$, Lin $\mathrm{H}$. Ultrasound diagnosis of complete uterine inversion in a nulliparous woman. Acta obstetricia et Gynecologica Scandinavica. 2012;91(3):379-81.

8. Occhionero M, Restaino G, Ciuffreda M, Carbone A, Sallustio G, Ferrandina G. Uterine inversion in association with uterine sarcoma: a case report with MRI findings and review of literature. Gynecologic and Obstetric Investigation. 2012;73(3):260-4.

9. Lewin JS, Bryan PS. MR imaging of uterine inversion. J Comput Assist Tomogr. 1989;13:357-9.

10. Fofie C, Baffoe P. Non-Puerperal Uterine Inversion: A Case Report. Gehana Med J. 2010;44:79-81.

11. Shabbir S, Ghayasuddin M, Younus SM, Baloch K. Chronic non-puerperal uterine inversion secondary to sub-mucosal fibroid. JPMA. 2014;64:586-8.

Cite this article as: Kalarani E, Amudha P, Rubini M, Karthika Devi A. Nonpuerperal inversion of uterus secondary to leiomyoma in menopause: a rare case report. Int J Reprod Contracept Obstet Gynecol 2016;5:2859-61. 